\title{
Aggressive behavior as a function of approval motivation and physical attack
}

\author{
STUART P. TAYLOR, Kent State \\ University, Kent, Ohin 44240
}

The relationship between physical aggression and approval motivation was investigated in 30 college males by allowing them to compete in a task involving reaction time with opponents who attempted to give them increasingly intense shocks. It was observed that while high need-for-approval Ss set low shocks under weak attack and increased their shock settings under increasing attack, the low need-for-approval Ss set intense shocks under all levels of attack.

In recent years, numerous researchers have hypothesized a relationship between approval motivation (social desirability responding) and the expression of aggression. Crowne \& Marlowe (1964), for example, state, "If approval-motivated persons are more dependent on the positive evaluations of others as a means of protecting a defensively enhanced picture of themselves, we might then expect that they would have greater problems in the recognition and expression of hostility." They add, "For approval-dependent individuals hostility would entail the threat of alienation of others, social rejection, unfavorable evaluations, and the resulting peril of damage to self-esteem [p. 133)." Conn \& Crowne (1964) theorize, with regard to aggressive behavior, that "Since the approval-dependent person places high value on preserving his social acceptability, he is unlikely to engage in such strongly disapproved behaviors [p. 164]." According to Fishman (1965), "The direct expression of aggression against others has strong negative sanctions in American Middle-class culture and tends to provoke disapproval and rejection. We might, therefore, expect that individuals strongly motivated toward gaining approval would tend to inhibit such unacceptable behavior [p. 809]."

The purpose of this experiment was to study the relationship between need for approval and the expression of overt physical aggression as a function of increasing physical attack.

\section{SUBJECTS}

The Ss were male undergraduates enrolled in an introductory psychology course at Kent State University. The extreme groups of $S s$ were selected from a total of 200 males tested on the Marlowe-Crowne Social Desirability to receive; (2) a ready signal, where the S pressed his finger down on a telegraph key; (3) the trial itself, where the $S$ released the key as quickly as possible; and (4) a feedback signal that consisted of a light that indicated the amount of shock that had been set for the $S$ by his opponent and, if the opponent was faster, the shock as well.

In establishing the intensities of shock to be administered to the $S$, the intensity judged "definitely unpleasant" was designated No. 5, No. 4 was set at $90 \%$ of that value, No. 3 at $80 \%$, No. 2 at $70 \%$, and No. 1 at $60 \%$.

need-for-approval low need-for-approval, and control groups, respectively, were: $22.4,7.7$, and 15.2 .

\section{PROCEDURE}

The $\mathbf{S}$ was seated at the task board (described in Taylor, 1967), and the shock electrode was attached to the left wrist. After the S's "unpleasantness" threshold for shock was determined, he heard a tape recording of the task instructions.

Each $S$ was told that he was competing on a task involving reaction time with another $S$ in an adjoining room. At the beginning of each trial, he was instructed to select (by pressing one of five buttons) any one of five intensities of shock he wished his opponent to receive. He was informed that the shock would be administered to his opponent at the end of a trial if he were faster than his opponent, and that he would receive the shock his opponent set for him if his opponent were faster. Thus, he realized that either he or his opponent would receive a shock, depending upon the outcome of the competition, and that both could select the intensity of the shock the other would receive.

Actually, there was no opponent. The frequency of wins and losses and the amount of shock received were programmed by the $\mathrm{E}$.

The task was then begun. All Ss received 29 trials. These consisted of one block of minimal attack trials, four blocks of increasing attack trials, plus an extra trial that was required to measure S's aggressive reaction to the feedback of the 28th trial. All Ss won $50 \%$ of the trials within each of the five blocks. The first block consisted of four trials in which the feedback settings were minimal, i.e., No. 1 . The second block (low attack) consisted of six trials in which the feedback settings averaged 1.5. In three of these trials, the shock setting was "one," and in the other three trials, "two." In the third block of six trials, the average shock setting was 2.5 , in the fourth block, 3.5 , and in the fifth and last block of trials (high attack), 4.5. Each trial consisted of four specific events: (1) a signal to set the degree of shock the $\mathrm{S}$ wished his opponent

\section{RESULTS}

Aggression was measured by the magnitude of shock $\mathrm{S}$ set for his opponent to receive.

In order to determine if there was an initial bias concerning shock selection, an analysis of variance was performed on the shock intensities set by Ss on the first trial, when Ss were required to select a shock intensity without knowledge of their opponents' aggressive intentions. According to this analysis, there were no differences among the three experimental groups in level of shock intensity set for the opponent $(F=.80, \mathrm{df}=2 / 27)$.

Minimal provocation did appear to influence differentially the shock-setting behavior of the experimental groups. The mean shock intensities set by the high need-for-approval, low need-for-approval, and control groups on Block 1 were, respectively, $1.82,3.02,1.60$. This group effect is significant at the .05 level ( $F=4.83$, df $=2 / 27$ ).

Figure 1 shows the mean aggression settings for each of the experimental groups for the four blocks of attack trials. According to an analysis of variance of mean aggression scores on the four blocks of trials, the differences in aggression among the three groups approach significance at the .05 level $(F=3.19$, $\mathrm{df}=2 / 27$ ). The exact probability value Furthermore, the increase in aggressiveness as a function of increasing attack, over all groups, is significant at the .001 level $(F=21.9$, df $=3 / 81)$.

A most interesting finding is that, while the "control" and high need-for-approval groups increased their shock-setting behavior as a function of increasing attack, the low need-for-approval group responded in a highly aggressive manner at all levels of attack. According to the analysis of variance, this interaction of groups and blocks is significant at the .005 level $(F=3.52, \mathrm{df}=6 / 81)$.

\section{DISCUSSION}

Presumably, high need-for-approval persons are motivated by a fear of losing associated with the group effect is .056 . 
Fig. 1. Mean aggression settings as a function of need approval and physical attack.

approval. Crowne \& Marlowe (1964) state, for example, that "the high need-for-approval individual has learned that conformity, submission, and the normative anchoring of his behavior entail the fewest risks of social rejection and threats to self-esteem [p. 202]." Since the expression of aggression is not condoned by society, many researchers believe that approval-oriented individuals would inhibit their aggressive tendencies for fear of losing social approval. They hypothesize, in other words, that high need-for-approval Ss, because of their inhibitory tendencies, will be less aggressive than low need-for-approval Ss. This inhibition hypothesis underlies all of the theorizing concerning the presumed relationship between need for approval and aggression.

The results of this experiment support the hypothesis concerning the relative aggressiveness of high and low need-for-approval Ss: The high need-for-approval $S$ s were less aggressive than the low need-for-approval Ss. However, the difference between the groups appears to be due to the inappropriately aggressive behavior of the low need-for-approval group rather than the inhibition of aggression on the part of the high need-for-approval group. The high need-for-approval $S s$ appeared to be responsive to the opponents' provocation; they set low shocks under low provocation and steadily increased the intensity of their shock settings as the opponent intensified the attack. In fact, there was little difference between the behavior of the Ss in the high approval-dependent group and the "control" group, composed of Ss with relatively moderate or "average" approval motivation. Low need-for-approval Ss, on the other hand, reacted in an intensely aggressive manner under all levels of provocation.

These results suggest that we should revise our conception of the relationship between approval motivation and aggression. Primarily, this author contends that whether or not an approval-oriented individual responds aggressively depends upon the particular social demands of the situation.

In this experiment, the $\mathrm{Ss}$ were confronted with an opponent who relentlessly increased the intensity of his attack. There are a number of strategies that could be used in this situation. For example, one strategy is to set high shocks continually, i.e., to punish the opponent in an attempt to convince him to lessen his

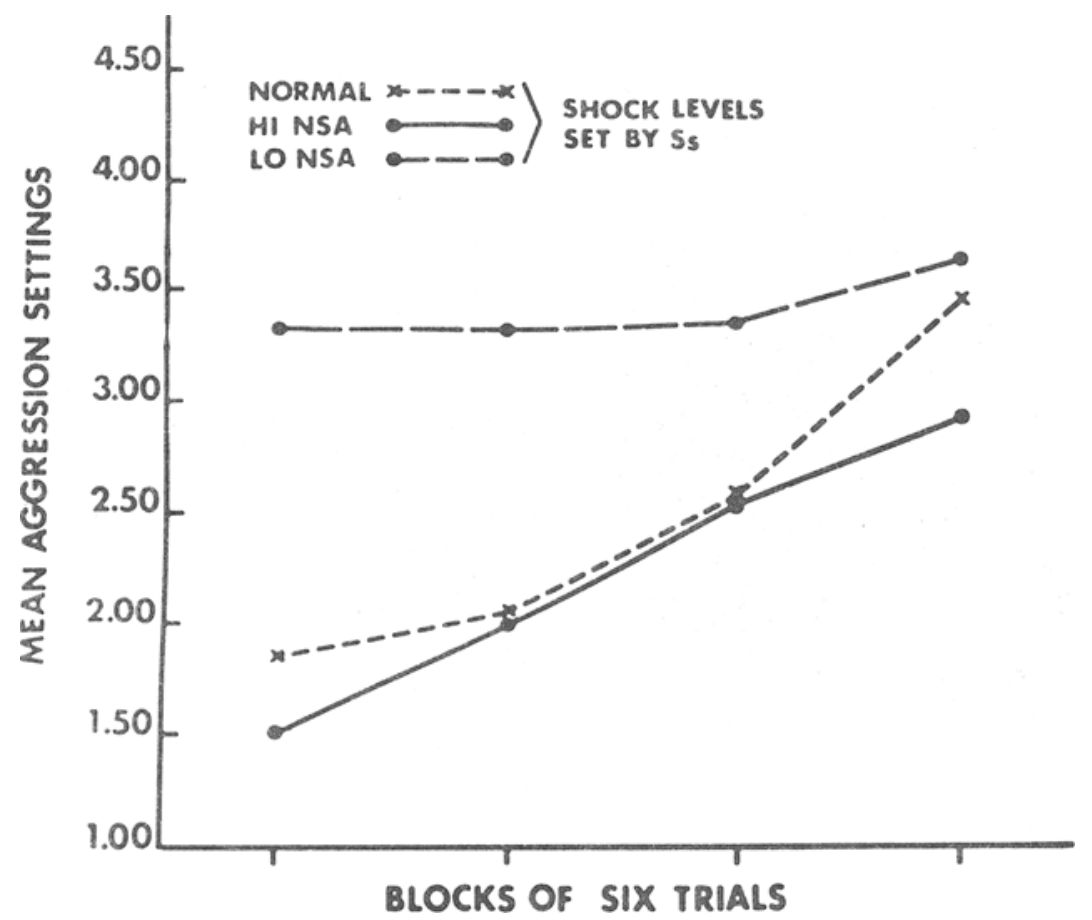

attack. The approval-oriented $S$ would be highly reluctant to utilize this approach, since the use of intense aggression is unacceptable in our society and, presumably, could lead to a loss of social approval. On the other hand, one could utilize a submissive strategy by continually setting low shocks. Although submissiveness might elicit a sympathetic response from an aggressor, it might also lead to a rapid decline in social approval since it smacks of cowardice. Given this highly ambiguous and conflicting situation, one might expect the approval-oriented individual to search for and conform to an external standard of comparison or model. In other words, he might conform to the behavior of the opponent. Of course, in a less ambiguous situation, for example, one in which intense aggression is rewarded, the high need-for-approval $S$ might behave in a more aggressive manner.

The behavior of the low need-for-approval $S$ should not be mediated by a fear of losing social approval. He should experience little "social anxiety" while setting high shocks or low shocks. Why, then, did he continuously set high shocks? It is the author's belief that the low need-for-approval $S$, being relatively free of social anxiety, interpreted the situation in a naive manner and set high shocks in order to simply "make the game more interesting." While conversing with these Ss, one had the decided impression that they "enjoyed" playing the game and were insensitive to the fact that their behavior was injurious to their opponents. They intimated that the challenge, the excitement, was increased by setting high shocks and attempting to "beat" the opponent. This interpretation is strengthened by the recent finding that $\mathrm{Ss}$ characterized by low social anxiety (as measured by the Lykkens Activity Preference Scale) evidence intense aggressiveness under all levels of provocation relative to a group of Ss characterized by high social anxiety (Dengerink, 1968).

\section{REFERENCES}

CONN, L. K., \& CROWNE, D. P. Instigation to aggression, emotional arousal, and defensive emulation. Journal of Personality, 1964, 32, 163-179.

CROWNE, D. P., \& MARLOWE, D. A. The epproval motive. New York: Wiley, 1964.

DENGERINK, H. Affective responsiveness, aggression and physiological arousal. Unpublished doctoral dissertation, Kent State University, 1968.

IISHMAN, C. G. Need for approval and the expression of aggression under varying conditions of frustration. Joumal of Personality \& Social Psychology, 1965, 2, 809-816.

TAYTOR, S. Aggressive behavior and physiological arousal as a function of provocation and the tendency to inhibit aggression. Journal of Personality, 1967, 35, 297-310. 